\title{
De novo t(1;6)(p13p21.3) Dengeli Resiprokal Translokasyonun İnfertilite ile İlișkisi
}

\author{
Murat KAYA 國, Gülçin BAĞATIR OZAN 國, Kıvanç ÇEFLE ${ }^{1}{ }^{1}$, Şükrü ÖZTÜRK ${ }^{1}$, \\ Şükrü PALANDUZ $\mathbb{1}^{1}$
}

\section{ÖZ}

İnfertilite tüm dünyada çiftlerin yaklaşık \%15'ini etkileyen önemli bir sağlık sorunudur. İnfertilite hem erkek hem de kadın kaynaklı faktörler ile ortaya çıkabilir. Vakaların yaklaşık \%40'ında tiyoloji belirsizdir. Dengeli resiprokal translokasyonlar, insanlarda en yaygın olarak karşılaşılan yapısal kromozom anomalileridir ve infertilite ile yakından ilişkilidir. Dengeli resiprokal translokasyonlar çoğunlukla taşıyıcıların fenotipini etkilemez ancak kromozomal olarak dengesiz gamet oluşturma yönünden bu kişiler anlamlı şekilde artmış riske sahiptir. 6p21.3 kromozomal bölgesi infertilite ile ilişkili birçok geni barındırmaktadır. 6p21.3 bölgesini içine alan dengeli resiprokal translokasyonlar genellikle infertilite ile ilişkilendirilmiştir. Bu çalışmada bilim dalımıza infertilite nedeni ile refere edilen çiftten yapılan karyotip analizi sonucunda erkekte tespit ettiğimiz $\mathrm{t}(1 ; 6)(\mathrm{p} 13 \mathrm{p} 21.3)$ dengeli resiprokal translokasyonun infertiliteyle ilişkisi üzerinde durulmuștur.

Anahtar Kelimeler: İnfertilite; dengeli resiprokal translokasyon; $\mathrm{t}(1 ; 6)$.

\section{The Relationship Between De novo t(1;6)(p13p21.3) Balanced Reciprocal Translocation and Infertility}

\begin{abstract}
Infertility is an important health problem affecting about $15 \%$ of couples all over the world. Infertility can occur because of a combined etiology where both female and male factors are combined. In nearly $40 \%$ of the patients, the etiology is unclear. Balanced reciprocal translocations are the most common structural chromosomal abnormalities in humans and they are closely related with infertility. Balanced reciprocal translocations mostly do not affect the phenotype of the carriers however, these individuals have a significantly increased risk in terms of chromosomally unstable gametes. The chromosomal region 6p21.3 contains many genes associated with infertility. Translocations involving the 6 p21.3 chromosomal region are generally associated with infertility. In this study, the relationship between infertility and $\mathrm{t}(1 ; 6)(\mathrm{p} 13 \mathrm{p} 21.3)$ balanced reciprocal translocation was discussed.
\end{abstract}

Keywords: Infertility; balanced reciprocal translocation; $\mathrm{t}(1 ; 6)$.

\section{Gíis}

İnfertilite, 12 aylık bir sürede düzenli korunmasız ilişkiye rağmen hamileliğin oluşmamasına denilmektedir. İnfertilite tüm dünyada çiftlerin yaklaşık \%15'ini etkileyen önemli bir sağlık sorunudur (1). Yapısal kromozomal anomaliler genel olarak çeşitli nedenlerle kromozomlarda kırıkların oluşması ve sonrasında bu kırılan bölgelerin anormal biçimde tekrar yapışmasıyla oluşurlar. Yapısal kromozomal anomaliler; translokasyon, inversiyon, insersiyon gibi alt gruplara ayrılır. Resiprokal translokasyon kromozomlarda kırılmalar sonucunda oluşan kromozom parçalarının kromozomlar arasında karşılıklı yer değiştirmesiyle oluşur. Bu değişimler genelde kromozomlarda materyal kaybına neden olmaz ve dengeli translokasyon olarak adlandırılır (2). Yaklaşık 600 yeni doğumda bir görülen dengeli resiprokal translokasyonlar çoğunlukla taşıyıcıların fenotipini etkilemez ancak kromozomal olarak dengesiz gamet oluşturma yönünden bu kişiler anlamlı şekilde artmış riske sahiptir. Bu kromozom anomalileri infertiliteye, tekrarlayan düşüklere ve anomalili çocukların doğmasına neden olabilirler (3). 
$\mathrm{Bu}$ olgu sunumu çalışmasında bilim dalımıza infertilite nedeni ile refere edilen çiftten yapılan karyotip analizi sonucunda erkekte tespit ettiğimiz $\mathrm{t}(1 ; 6)(\mathrm{p} 13 \mathrm{p} 21.3)$ dengeli resiprokal translokasyonun infertiliteyle ilişkisi üzerinde durulmuştur. Bildiğimiz kadarıyla olgumuzda tespit ettiğimiz bu dengeli resiprokal translokasyonun infertilite ile ilişkisini gösteren çalışma daha önce literatürde bildirilmemiştir. Hasta ve eşinden bilgilendirilmiş onam formu alınmıştır.

\section{Olgu}

Dört yıldır evli olan 25 yaşında bir erkek vaka ve 24 yaşındaki sağlıklı eşi infertilite sebebiyle sitogenetik analiz için bilim dalımıza refere edilmiştir. İki erkek kardeşi olan olgunun anne-babasının anomalili çocuk öyküsü veya tekrarlayan düşük öyküsü bulunmamaktadır. Probandın 2 kardeşinden birinin 3 diğerinin 2 sağlıklı çocuğa sahip olduğu öğrenilmiştir. Vakanın ailesinin kromozom anomalisi ile ilişkilendirilebilecek aile öyküsünün olmadığı tespit edilmiştir. D1ş merkezde yapılan semen analizi sonucuna göre vakanın oligospermi olduğu anlaşılmıştır. Olgunun temel hormon seviyelerinin normal değerlerde olduğu görülmüştür. [ [ $\mathrm{LH} \quad(6,86$ $\mathrm{IU} / \mathrm{mL})$, total testosteron $(3,76 \mathrm{ng} / \mathrm{mL})$ ve $\mathrm{FSH}(7,82$ $\mathrm{mIU} / \mathrm{mL})$ ]. Y kromozomuna yönelik mikro delesyon analizi bilim dalımızda yapılmış olup AZFa, AZFb, AZFc ve AZFd bölgelerinde delesyon olmadığı tespit edilmiştir. Akraba olmayan olgu ve eşinden alınan periferik kandan karyotip analizi yapılmıştır. Yaptığımız klasik sitogenetik çalışmada kısaca, periferik kan lenfositleri fitohemaglutinin (PHA) ile indüklenmiş ve 72 saatlik kültürde bekletilmiştir. Harvest aşamasından sonra yayma işılemi yapılmış ve üzerinde metafaz kromozomları olan lamlar GTG bantlama ile boyanmıştır. Sayısal ve yapısal kromozom değerlendirilmesi 25 metafaz plağı üzerinden yapılmıştır. Olgunun 46,XY, $\mathrm{t}(1 ; 6)(\mathrm{p} 13 \mathrm{p} 21.3)$ dengeli translokasyon taşıyıcısı olduğu, eşinin ise 46,XX normal karyotip yapısına sahip olduğu ortaya çıkmıştır. Probandın karyotip görüntüsü Şekil 1'de gösterilmiştir.

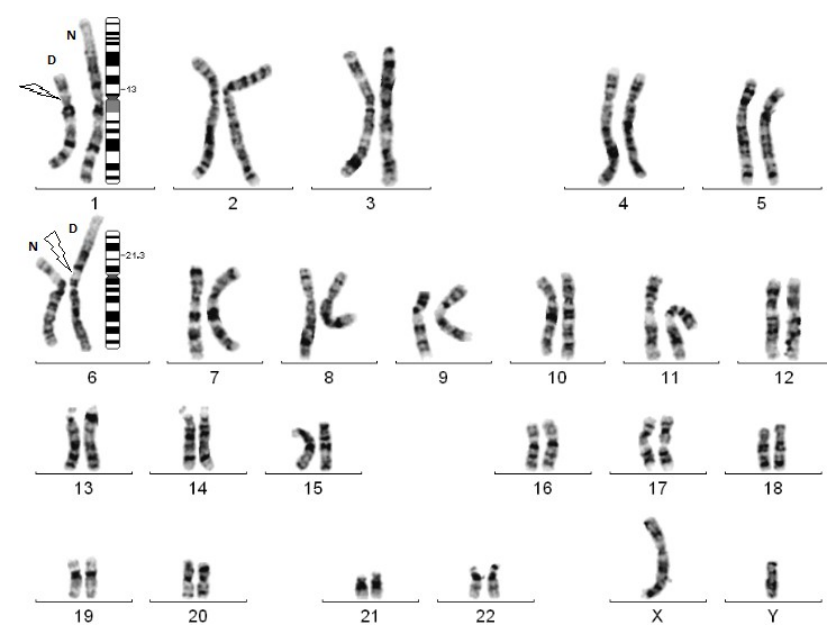

Şekil 1. Olguya ait karyotip örneği (1. ve 6. kromozomlar arasında translokasyon sonucu oluşan derivatif kromozomlar ' $D$ ' harfi ile simgelenmiştir. ' $N$ ' harfi ile gösterilen kromozomlar ise normal 1 ve 6 'dır. 1 . ve 6. kromozomların kırılma bölgeleri idiyogram üzerinde gösterilmiştir)
Tespit edilen dengeli translokasyonun de novo olup olmadığının anlaşılması için vakanın anne ve babasına da kromozom analizi yapılmış ve her ikisinin de normal karyotip kuruluşuna sahip olduğu anlaşılmıştır.

\section{TARTIŞMA}

Karyotip analizi, translokasyonları da içine alan çeşitli dengeli kromozom anomalilerinin belirlenmesinde uzun zamandır başarılı şekilde kullanılmaktadır. Genom hakkında önemli bilgiler sunan karyotip analizinin en büyük dezavantajı yaklaşık 5 Mb'dan daha küçük değişiklikleri tespit edememesidir (4). $\mathrm{Bu}$ nedenle sitogenetik olarak dengeli gibi gözüken bazı kromozomal değişiklikler moleküler seviyede dengesiz olabilirler. Örneğin kromozomların kırılma noktalarında spermatogenez ile ilişkili genler veya fenotipi etkileyebilecek genler yer alabilir. Bu genlerin yapısı kromozomdaki kırılmalar nedeniyle bozulabilir. $\mathrm{Bu}$ yüzden sitogenetik olarak dengeli kromozomal translokasyon veya inversiyon tespit edilen bazı kişilerde infertilite oluşabilir veya ilgili genin fonksiyonuna göre bu bireyler fenotipik olarak etkilenebilir (5).

Olgumuzda tespit edilen translokasyon bölgelerinden birisi 6p21.3’tür. Literatürde 6. kromozomun 6p21.3 bölgesinde veya bu noktaya yakın bölgedeki kırılmalar ile oluşan pek çok translokasyon taşıyıcısı olgu bildirilmiştir $(6,7)$. 6p21 ve 6 p22 bölgelerinin infertilite ile ilişkili olduğu ve bu bölgelerin translokasyonlar açısından hotspot bölgeler olduğu bilinmektedir (8). Yapılan çalışmalar 6p21.32 kromozomal bölgesinde yer alan HLA-DRB6, HLA-DQA1, HLA-DQA2, HLA-DQB1AS1, STK19P, C4A ve daha birçok genin infertile ile ilişkili olabileceğini göstermiştir (9). Yakın zaman önce yapılan çalışmada infertil ve normal bireylerin spermatozoa DNA'larındaki metilasyon farklılıkları araştırılmş ve infertil bireylerde 6p21.3’te yer alan HLADRB6 ve HLA-DQA1 genlerinin hipermetile olduğu tespit edilmiştir (10). İnfertilite ile ilişkilendirilmiş ve 6p21.31'de bulunan bir başka gen de SLC26A8 genidir. $\mathrm{Bu}$ genin sperm hareketinde hayati rol üstlendiği bildirilmiştir. Yapılan çalışmalarda sperm hareketi azalmış infertil bireylerde bu gende çeşitli mutasyonların olduğu gösterilmiştir (11). Yine 6.kromozomun bahsedilen bölgesine lokalize olan, epididimis ve testiste bolca ifade edilen genlerden GPX5, ZNF165 ve ZNF76 genlerinin infertilite ile ilişkili olabileceği bildirilmiştir (12). Olgumuzda tespit edilen translokasyondaki diğer kromozomal kırık bölge ise 1p13'tür ve bu kromozomal bölgedeki translokasyonların da infertilite ile ilişkili olabileceği bildirilmiştir (13).

Sitogenetik olarak dengeli gibi gözüken ancak fenotipi bir şekilde etkileyen kromozomal değişimlerin moleküler boyutta araştırılmasını amaçlayan çeşitli çalışmaların sayısı son yıllarda artmaya başlamıştır $(14,15)$. Buna rağmen dengeli kromozom değişimleri ve infertilite arasındaki ilişkinin moleküler seviyede aydınlatılması ile ilgili yapılan araştırma sayısı sınırlıdır. Yakın gelecekte bu araştırmaların sayısının artışıyla ve araştırmada kullanılacak tekniklerin daha da gelişmesiyle sitogenetik olarak dengeli kromozom anomalileri ve infertilite arasındaki ilişki daha net ortaya çıkacaktır.

$\mathrm{Bu}$ bilgiler 1şı̆̆ında $\mathrm{t}(1 ; 6)(\mathrm{p} 13 \mathrm{p} 21.3)$ saptanan olgumuzun 6. ve/veya 1. kromozomların translokasyon sonucu 
kırılan bölgelerinde yer alan infertilite ile ilişkili genlerin yapısının bozulmasına bağlı olarak olgumuzda infertilite oluşmuş olabilir. $\mathrm{Bu}$ nedenle olgumuz gibi sitogenetik olarak dengeli kromozom anomalisi taşıyan vakaların ilgili kromozomlarındaki kırık bölgelerinin moleküler açıdan değerlendirilmesinin önemli olduğunu düşünüyoruz.

Maddi destek ve çıkar ilişkisi: Çalışmayı maddi olarak destekleyen kişi/kuruluş yoktur ve yazarların herhangi bir çıkara dayalı ilişkisi bulunmamaktadır.

\section{KAYNAKLAR}

1. Poongothai J, Gopenath TS, Manonayaki S. Genetics of human male infertility. Singapore Med J. 2009; 50(4): 336-47.

2. Theisen A, Shaffer LG. Disorders caused by chromosome abnormalities. Appl Clin Genet. 2010; 3: 159-74. doi: 10.2147/TACG.S8884.

3. De P, Chakravarty S, Chakravarty A. Novel balanced chromosomal translocations in females with recurrent spontaneous abortions: two case studies. J Hum Reprod Sci. 2015; 8(2): 114-7.

4. Utami KH, Hillmer AM, Aksoy I, Chew EG, Teo AS, Zhang Z, et al. Detection of Chromosomal Breakpoints in Patients with Developmental Delay and Speech Disorders. PLoS One. 2014; 9(6): e90852.

5. Zhang H, Wang R, Li L, Jiang Y, Zhang H, Liu R. Clinical feature of infertile men carrying balanced translocations involving chromosome 10: case series and a review of the literature. Medicine (Baltimore). 2018; 97(15): e0452.

6. Paoloni-Giacobino A, Kern I, Rumpler Y, Djlelati R, Morris MA, Dahoun SP. Familial t(6;21)(p21.1;p13) translocation associated with male-only sterility. Clin Genet. 2000; 58(4): 324-8.

7. Berner AL, Bağci S, Wohlleber E, Engels E, Müller A, Bartmann P, et al. Familial translocation $\mathrm{t}(6 ; 20)(\mathrm{p} 21 ; \mathrm{p} 13)$ resulting in partial trisomy $6 \mathrm{p}$ and partial monosomy 20p: report of a new case and review of the literature. Cytogenet Genome Res. 2012; 136(4): 308-13.

8. Lee JY, Dada R, Sabanegh E, Carpi A, Agarwal A. Role of genetics in azoospermia. Urology. 2011; 77(3): 598-601.

9. Jiang T, Wang Y, Zhu M, Wang Y, Huang M, Jin G, et al. Transcriptome-wide association study revealed two novel genes associated with nonobstructive azoospermia in a Chinese population. Fertil Steril. 2017; 108(6): 1056- 62.e4.

10. Sujit KM, Sarkar S, Singh V, Pandey R, Agrawal NK, Trivedi S, et al. Genome-wide differential methylation analyses identifies methylation signatures of male infertility. Hum Reprod. 2018; 33(12): 225667.

11. Dirami T, Rode B, Jollivet M, Da Silva N, Escalier D, Gaitch N, et al. Missense mutations in SLC26A8, encoding a sperm-specific activator of CFTR, are associated with human asthenozoospermia. Am J Hum Genet. 2013; 92(5): 760-6.

12. Truong BN, Moses EK, Armes JE, Venter DJ, Baker HW. Searching for candidate genes for male infertility. Asian J Androl. 2003; 5(2): 137-47.
13. Wang RX, Zhang HG, Pan Y, Chen S, Yue FG, Zhu DL, et al. Translocation breakpoints of chromosome 1 in male carriers: clinical features and implications for genetic counseling. Genet Mol Res. 2016; 15(4): 1-7. doi: 10.4238/gmr.15048707.

14. Lango Allen H, Caswell R, Xie W, Xu X, Wragg C, Turnpenny PD, et al. Next generation sequencing of chromosomal rearrangements in patients with splithand/split-foot malformation provides evidence for DYNC1I1 exonic enhancers of DLX5/6 expression in humans. J Med Genet. 2014; 51(4): 264-7.

15. Dong Z, Wang H, Chen H, Jiang H, Yuan J, Yang Z, et al. Identification of balanced chromosomal rearrangements previously unknown among participants in the 1000 Genomes Project: implications for interpretation of structural variation in genomes and the future of clinical cytogenetics. Genet Med. 2017; 20(7): 697-707. 